\title{
Adding pieces to the Alice in wonderland syndrome puzzle: a comment to the paper by Brooks and colleagues
}

\author{
Adicionando peças ao quebra-cabeça da síndrome de Alice no país das maravilhas: \\ um comentário ao artigo por Brooks e colegas
}

Alessandro VIGANÒ', Giulio MAESTRIA², Valentina MANCINI', Vittorio DI PIERO ${ }^{4,5}$

Dear Editor,

We have read with great interest the paper by Brooks and colleagues about their patient experiencing Alice in Wonderland syndrome (AIWS), following a brain hemorrhage. Interestingly, the patient had a past medical history of migraine with aura (MA); and AIWS, although secondary to a hemorrhage, was followed by a pulsatile headache ${ }^{1}$. We appreciate the effort of the authors to combine results from different case reports to draw a clearer pattern of AIWS. To date, the pathophysiology of AIWS remains elusive and far to be fully understood. By reading the paper by Brooks et al. ${ }^{1}$, two questions come to mind. First, is AIWS due to alterations in a specific brain region or rather a more complex fronto-temporal-parietal network? Second, why are patients with migraine more prone to experience AIWS than the other neurological patients, and why do they often have migraine at the same time they have AIWS?

Below, we reported two cases that might help in finding answers to these questions. Recently, we described the occurrence of AIWS associated to migraine headache in a 54-yearold man, with a history of migraine without aura $(\mathrm{MoA})^{2}$. The patient did not have migraine attacks in the year prior to the AIWS. During the AIWS episode, he saw computer icons going out of the screen and moving in the space between him and the screen. Neuroimaging investigations showed a glioblastoma on the left temporal-occipital junction (TOJ). This case suggested that TOJ and associative areas of the parietaltemporal-occipital carrefour are probably the most involved in the development of AIWS symptoms. As presented by Brooks and colleagues, most lesions in the reported case series are located very close to this region. Even in our case, AIWS was followed by migrainous headache. Symptoms' timing was consistent with an aura rather than a seizure (moreover, EEG excluded epileptic activity), suggesting that AIWS was associated to the patient's first migraine aura.

In this line, a second case ${ }^{3}$, of a 47-year-old woman, who suffered from MA may help clarifying how AIWS and MA are related. The patient had visual MA since her adolescence. Few years ago, she started having a progressive modification of her aura features. Instead of her typical scotoma, she experienced a mosaic vision, that was subsequently associated to feelings of elongation and dismemberment of her left arm, depersonalization and slowing in temporal perception. These episodes lasted up to six hours and were followed by migrainous headache. She started a pharmacological therapy for major depression, and, after some lines of treatment, she was prescribed with aripiprazole. She discontinued and restarted aripiprazole several times, according to her mood and, invariantly, on the first day of treatment with aripiprazole she experienced the AIWS symptoms previously described. We performed a SPECT during an episode of AIWS and found a marked hypoperfusion of the right primary somatosensory area with a corresponding hyperperfusion of the homolateral precuneus. The hypoperfusion area was compatible with that involved in the cortical spreading depression (CSD), the neural correlate of the aura ${ }^{4}$.

\footnotetext{
${ }^{1}$ IRCCS Fondazione Don Carlo Gnocchi, Milano, Italia.

2University of Lausanne, Centre Hospitalier Universitaire Vaudois (CHUV), My Space Lab, Department of Clinical Neuroscience, Lausanne, Switzerland.

${ }^{3}$ University of Geneva School of Medicine, Developmental Imaging and Psychopathology Laboratory, Geneva, Switzerland.

«Sapienza Università di Roma, Dipartimento di Neuroscienze Umane, Roma, Italia.

${ }^{5}$ Consorzio Universitario per i Disordini Adattativi e la Cefalea, Pavia, Italia.

PaviaAlessandro VIGANÒ iD https://orcid.org/0000-0002-8079-5354; Giulio MAESTRIA ID https://orcid.org/0000-0003-2900-1480;

Valentina MANCINI iD https://orcid.org/0000-0003-4411-896X; Vittorio DI PIERO (iD) https://orcid.org/0000-0002-2631-7562

Correspondence: Alessandro Viganò; Fundação IRCCS Don Carlo Gnocchi, Via A. Capecelatro 66, 20148, MIlan, Italia; E-mail: alessandro.vigano1@unimi.it

Conflict of interest: There is no conflict of interest to declare.
}

Received on November 5, 2019; Accepted on November 15, 2019.

(cc) BY 
In our review on the topic ${ }^{5}$, we hypothesized that one of the main sources of AIWS symptoms is an imbalance between primary and secondary sensory regions. In our hypothesis, AIWS can be triggered by an anatomical or functional alteration of the normal information flow through sensory networks. Migraineurs are more likely to develop CSD, which is an example of a transient and fully reversible functional impairment of the neuronal activity, occurring mainly in cortical primary areas. CSD might, therefore, facilitate the disconnection of these primary areas from their respective secondary associative areas, producing a mismatch between the volume of inputs inflow and the inner representation of the self. Associative area with a higher level of multimodality (e.g. TOJ, cuneous/precuneous) can more easily induce intense alterations of the representation between the self and enviroment ${ }^{5}$. Interestingly, the case reported by Brooks and colleagues showed a lesion in the precuneus area.

In conclusion, although there is encouraging evidence that we will reach a comprehensive insight on the pathophysiology of AIWS, further investigations on neuronal correlates of AIWS are needed to obtain a valid theory.

\section{References}

1. Brooks JBB, Prosdocimi FC, Rosa PBD, Fragoso YD. Alice in Wonderland syndrome: "Who in the world am I?". Arq Neuropsiquiatr. 2019 Sep 23;77(9):672-4. http://dx.doi.org/10.1590/0004$282 \times 20190094$

2. Mastria G, Mancini V, Viganò A, De Sanctis R, Letteri F, Toscano $\mathrm{M}$, et al. Temporal-occipital glioblastoma presenting with Alice in Wonderland Syndrome in a patient with a long-time history of migraine without aura. Neurocase. 2018 Oct/Dec;24(5-6):242-4. https://doi.org/10.1080/13554794.2018.1562079
3. Mancini V, Mastria G, Frantellizzi V, Viganò A, Petsas N, Sollaku S, et al. Aripiprazole-Triggered Alice in Wonderland Syndrome Episodes Studied with 99mTc-HMPAO Brain SPECT. Eur Neurol. 2018;79(56):333-4. https://doi.org/10.1159/000490902

4. Charles AC, Baca SM. Cortical spreading depression and migraine. Nat Rev Neurol. 2013;9(11):637-44. https://doi.org/10.1038/nrneurol.2013.192

5. Mastria G, Mancini V, Viganò A, Di Piero V. Alice in Wonderland Syndrome: a clinical and pathophysiological review. Biomed Res Int. 2016;2016:8243145. https://doi.org/10.1155/2016/8243145 